\title{
Energy and environment - An introduction
}

\author{
Giang Minh Hoang ${ }^{1} \cdot$ Wannapawn Watsuntorn ${ }^{2,3} \cdot$ Warawut Chulalaksananukul ${ }^{2,3} \cdot$ Raj Mohan Balakrishnan $^{4} \cdot$ \\ Eldon R. Rene ${ }^{5}$
}

Published online: 18 February 2021

(C) The Author(s), under exclusive licence to Springer-Verlag GmbH, DE part of Springer Nature 2021

This special issue covers important research themes related to pollution control and resource recovery in water, air, and soil/ solid environments. With the advent of new technologies and innovations in the field of applied sciences, waste treatment has been combined with resource recovery, e.g., biogas, biofuel, water for reuse, biochemicals, and fertilizers. Microorganisms are ubiquitous in the biosphere. The most significant importance of the microbes on earth is their roles to recycle the elements involving biogeochemical cycles (carbon, nitrogen, sulfur, phosphorus, silicon, and metals). For example, based on the microbial metabolism of respiration and fermentation, several organic compounds can be broken into smaller molecule such as carbon dioxide $\left(\mathrm{CO}_{2}\right)$. On the other hand, the release of $\mathrm{H}_{2} \mathrm{~S}$ gas from hot springs, crude petroleum, volcanic gases, refineries, sewage treatment industries, and paper mills has also shown to cause significant human health and environmental hazards. For the treatment of odors (e.g., $\mathrm{H}_{2} \mathrm{~S}$ and $\mathrm{NH}_{3}$ ) and volatile organic compounds (VOCs such as benzene and toluene), various approaches have been developed based on physical, chemical, and biological processes. Biological processes to remove pollutants present in gas and liquid phases have been suggested as a suitable strategy because it has demonstrated to be energy efficient, cost-effective, and yield high removal of the pollutant, under both steady and transient operating conditions.

Nowadays, the current linear production, consumption, and disposal models are no longer adequate due to the ineffective production and use of energy resources. Besides, the world's energy production and consumption pattern are not eco-friendly and environmentally sustainable. To reduce the use of fossil fuels, mitigate the associated climate effects, and minimize the impacts associated with landfilling, the waste sector, as well as all other renewable energy resources, must be employed. Waste and energy management sectors can play an essential role in facilitating a circular bioeconomy. Besides, energy recovery from waste can also be a part of this industrial symbiosis networks. Thus, an improvement of integrated waste management contributes to enhanced economic and environmental efficiencies in well-known processes such as anaerobic digestion of liquid and solid wastes.

In developing countries, waste-to-energy technologies are getting more attention from different stakeholders because of their potential to reduce landfilling and greenhouse gas emission. However, the low calorific value of waste due to its high-water content becomes a challenge for economic and environmental effectiveness of energy recovery practices. Also, combining technologies by considering the geographical characteristics, future

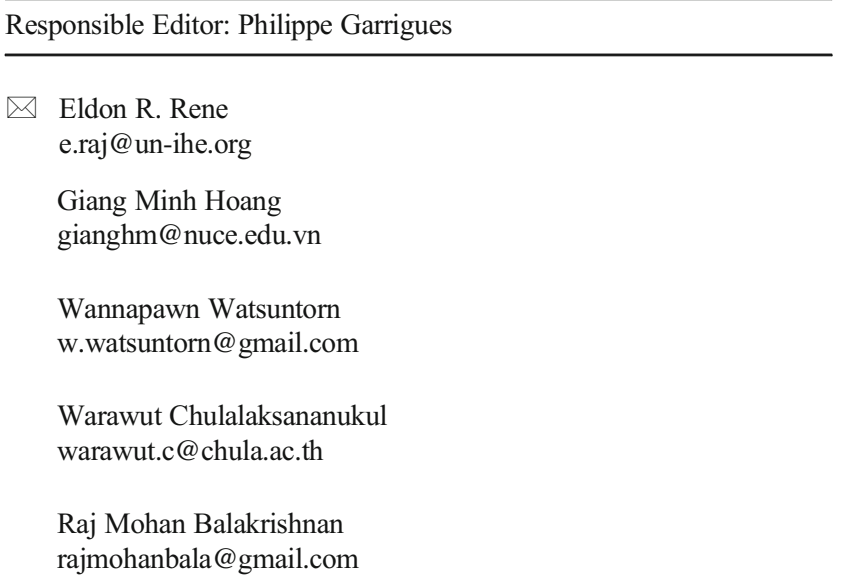

1 Department of Environmental Technology and Management, Faculty of Environmental Engineering, National University of Civil Engineering, 55 Giai Phong road, Hanoi 113021, Vietnam

2 Biofuels by Biocatalysts Research Unit, Faculty of Science, Chulalongkorn University, Bangkok, Thailand

3 Department of Botany, Faculty of Science, Chulalongkorn University, Bangkok, Thailand

4 Department of Chemical Engineering, National Institute of Technology Karnataka Surathkal, Surathkal, India

5 Department of Water Supply, Sanitation and Environmental Engineering, IHE Delft Institute for Water Education, Delft2601DA, The Netherlands 
trends of waste generation, source separation/on-site treatment, and incinerator can efficiently recover energy from municipal solid wastes (MSWs). The collection of papers presented in this special issue covers appropriate technologies that consider local conditions and promote energy recovery and circular economy in the region. Characteristics and circular economy play a significant role in effective energy recovery and environmental management. This special issue will provide valuable networking opportunity and set the stage for further cooperation among professionals from many Asian countries. The guest editors of this EEM-2019 special issue are thankful to the Editor-in-Chief of Environmental Science and Pollution Control (ESPR), Prof. Philippe Garrigues, for providing an opportunity to publish selected peer-reviewed papers that were presented at the following international/national conferences: (i) International Forum on Green Technology and Management (IFGTM-2019), an annual international event initiated by the Consortium for Green Technology Management and Research (CGTMR), Vietnam; (ii) The First International Conference on Biotechnology, Bioengineering, Biorefinery and Pollution Prevention (BBBP 2019) held at Chulalongkorn University, Thailand; and (iii) National Symposium on Environmental Pollution Prevention and Control: Future Perspective (EPPC:FP-2019), conducted by NITK Surathkal, India. Our special thanks to Ms. Fanny Creusot and Ms. Florence Delavaud, Editorial Assistants of ESPR, and the entire production team at Springer for their valuable support in bringing out this issue successfully. The guest editors firmly believe that the special issue papers will be a useful reading document to your research group, and we wish you all the very best.

Publisher's note Springer Nature remains neutral with regard to jurisdictional claims in published maps and institutional affiliations.

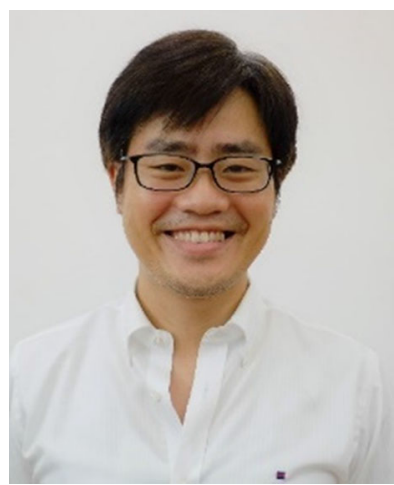

Minh Giang Hoang is an Assistant Professor at the National University of Civil Engineering (NUCE), Vietnam. Dr. Giang received a B. Eng in Environmental Engineering from NUCE in 2006, an MSc (2010) in Environmental Engineering from Politecnico di Milano, Italy, and a $\mathrm{PhD}$ (2017) in Environmental Science from Okayama University, Japan. Currently, he teaches undergraduate/graduate courses of solid waste management and environmental data analysis at NUCE. His research interest focusses on sustainable solid waste management including solid waste characterization and waste recycling technologies.

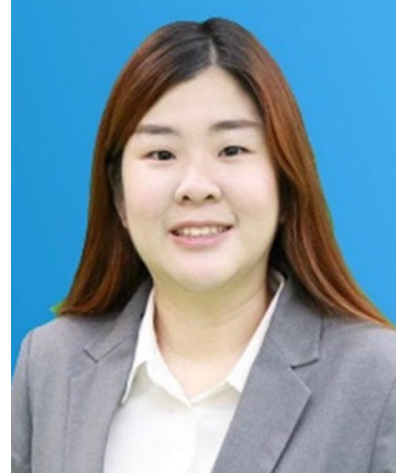

Dr. Wannapawn Watsuntorn is a postdoctoral researcher from Chulalongkorn University, Thailand. Dr. Watsuntorn completed her Bachelor's degree in Genetics in 2012 and a PhD in Biotechnology in 2017 from Chulalongkorn University, Thailand. Her PhD research focused on the removal of hydrogen sulfide using pure culture of Paracoccus versutus strain MAL1HM19, nitrate-reducing, sulfide oxidizing bacteria (NR$\mathrm{SOB}$ ) isolated from hot spring, in anoxic bioreactors. Her current work mainly focuses on the isolation of oleaginous yeasts from natural and industrial sources of Thailand and enhancement of their lipid production.

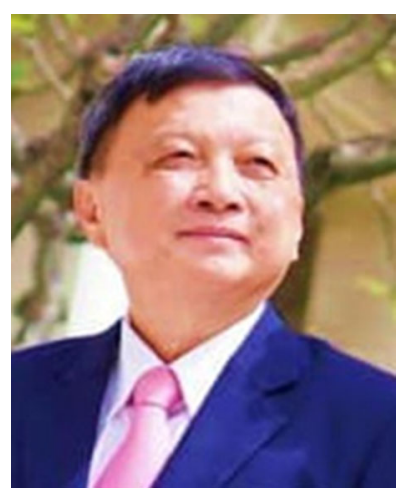

Prof. Dr. Wa ra w u t Chulalaksananukul completed his bachelor and master degrees from Chulalongkorn University, between 1977 and 1983. After graduation, he became one of the staff members of the Department of Botany, Faculty of Science, Chulalongkorn University. After 3 years of work, he got the fellowship from the French government to further his study in the fields of Microbiology and Biotechnology in France. He got another master diploma in 1989 and was awarded his first honor PhD level from INSA, Toulouse, France in 1993. Currently, he is the head of Biofuels by Biocatalysts Research Unit Deputy of Chulalongkorn University, Board of Genetics Society of Thailand, and of The Science Society of Thailand under the Patronage of his Majesty, the King of Thailand.

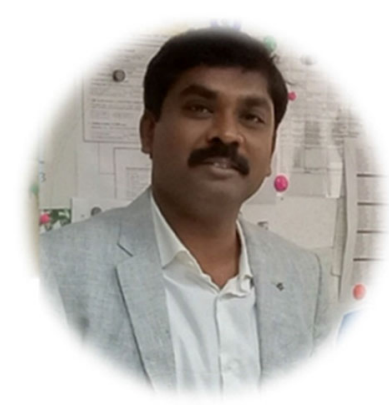

Dr. Raj Mohan Balakrishnan is a Professor at the Department of Chemical Engineering at National Institute of Technology Karnataka Surathkal, India. He graduated with a B.Tech degree in Chemical Engineering, Vellore Institute of Technology, Madras University in 1998, a postgraduation in M.Tech Industrial Pollution Control from NITK Surathkal, in 2000, a PhD from the Indian Institute of Technology Kharagpur, West Bengal, India in 2008, and a postdoctoral degree from the University of Ulsan, South Korea in 2009. He works in the area of air pollution control and abatement, solid waste management, advanced water treatment, resource recovery/reuse technologies, and bio-nanotechnology. 


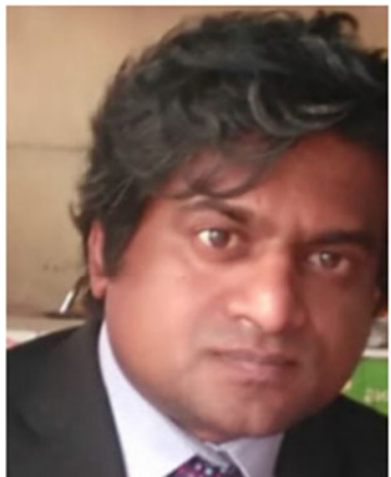

Eldon R. Rene $(\mathrm{PhD})$ is currently working as a Senior Lecturer at IHE Delft Institute for Water Education, The Netherlands. He obtained his University Teaching Qualification (UTQ) diploma from IHE Delft and a PhD in Chemical Engineering from the Indian Institute of Technology Madras (India). Eldon's broad research interests are related to the development of biological treatment processes for wastewater and waste-gas treatment, resource recovery, and the use of artificial intelligence tools for environmental monitoring and environmental process control. 